李娇 $1,{ }^{*}$, 金谷 ${ }^{2}$, 姚奇志 ${ }^{1}$, 李玲玲 1 , 刘红瑜 ${ }^{1}$

1 化学国家级实验教学示范中心(中国科学技术大学), 合肥 230026

2 中国科学技术大学化学与材料科学学院, 合肥 230026

摘要: “中学生英才计划” 是国家为培养科技创新后备人才所开展的一项培养计划。“英才计划” 夏令营活动是整 个培养计划中的一个重要体验和实践环节, 以 2019 年英才计划化学学科夏令营为例, 介绍具体的实践方向和关于 中学生拔尖人才培养的一点思考, 以期与同行共同探讨。

关键词: 中学生英才计划; 拔尖人才; 创新型后备人才

中图分类号: G64; O6

\title{
Reflection on the Cultivation Process of the Top Talents in "Elite Program for Senior High School Students": Taking the 2019 Elite Program Summer Camp as an Example
}

\author{
Jiao Li ${ }^{1,}{ }^{*}, \mathrm{Gu}$ Jin ${ }^{2}$, Qizhi Yao ${ }^{1}$, Lingling Li ${ }^{1}$, Hongyu Liu ${ }^{1}$ \\ ${ }^{1}$ National Demonstration Center for Experimental Chemistry Education (University of Science and Technology of China), \\ Hefei 230026, China. \\ ${ }^{2}$ School of Chemistry and Materials Science, University of Science and Technology of China, Hefei 230026, China.
}

\begin{abstract}
The "Senior High School Students Elite Program" is a training program developed by the State to train top-notch talents for scientific and technological innovation. The "elite plan" summer camp is a key part for experience and practice. Taking the summer camp of the 2019 Elite Program as an example, this paper introduces the specific practice direction and some thoughts on the training of top-notch talents for middle school students, hoping to explore with the colleagues.
\end{abstract}

Key Words: Senior High School Elite Program; Top Talent Training Program; Innovative reserve talent

英才计划是中学生科技创新后备人才培养计划, 中国科协、教育部于 2013 年开始逐步实施英才 计划, 其宗旨是贯彻全国科技创新大会精神, 落实《国家中长期教育改革和发展规划纲要 $(2010-$ 2020)》关于 “支持有条件的高中与大学、科研院所合作开展创新人才培养研究和试验, 建立创新人 才培养基地” 的要求, 发现和培养一批具有科学潜质的科技创新后备人才 ${ }^{[1-3]}$ 。通过在中学里面篮选 一批品学兼优的学生进入重点大学, 选拔一批品学兼优、学有余力, 具有创新潜质的中学生走进大 学, 在自然科学基础学科领域的著名科学家指导下参加科学研究项目、科技社团活动、学术研讨和

收稿: 2020-08-07; 录用: 2020-09-14; 网络发表: 2020-10-09

“通讯作者, Email: 1ijiao08@ustc.edu.cn

基金资助: 安徽省级教学改革项目(2018jyxm1040); 中国科学技术大学教学改革项目(2019xjyxm040); 研究生教学改革项目(2019jyy12) 
科研实践等活动。在为期一年的培养过程中, 感受名师魅力, 体验科研过程, 激发科学兴趣, 提高 创新能力, 树立科学志向。英才计划夏令营活动是整个计划一年期过程中的一个重要体验和实践环 节, 以2019年英才计划化学学科夏令营为例, 予以简单介绍。

\section{1 夏令营活动简介}

继英才计划化学学科夏令营活动在上海交通大学、吉林大学、浙江大学等一系列名校成功开展 后, 2019年7月22-26日, 2019年英才计划化学学科夏令营在中国科学技术大学举办, 来自天津、上 海、安徽、福建等 18 个省市的 46 名英才计划化学学科学生参加活动 ${ }^{[4]}$ 。通过科研大匠面对面的讲座 活动, 加深学生对化学学科的认识, 激发化学学习的浓厚兴趣; 中学生们走进大学化学实验室, 通 过探索实验活动, 在实践中体验化学的奥秘; 通过参观中国科学院等离子体物理研究所、中国科学 院强磁场科学中心、中国科学技术大学国家同步辐射实验室等国家重大科技场所, 点燃学生们的科 学梦想, 见图1。

中学生 “英才计划” 化学学科夏令营活动
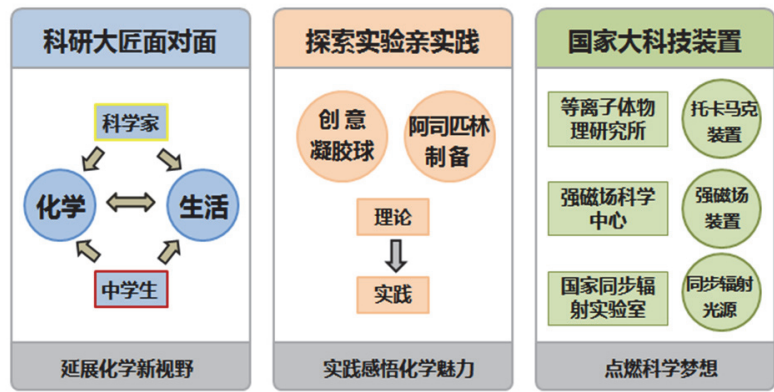

图1 英才计划化学学科夏令营活动框架

\section{2 科研大匠面对面：开拓眼界, 明晰科研梦想}

在本次夏令营活动中, 中国科学技术大学校长包信和教授作了题为 “能源的明天, 人类的未 来一一化学家的解决方案” 的精彩报告(见图2-左上), 向学生介绍日常生活中的能源, 讲述人类能源 的历史和未来。俞书宏教授、何平笙教授以及罗毅教授分别给学生带来 “如何热爱科学? 一一从纳 米科技谈起” (见图2-右上)、“高分子时代” “理性的化学——化学的理性” (见图2-左下)三场精彩的 大师报告。专家们风趣的语言以及贴近生活的报告内容, 激发了中学生学习、探究化学学科的兴趣, 增强了学生的创新意识及创新素养。会后与著名科学家面对面交流, 零距离感受大师风采, 学生们 都非常激动，感慨收获颇丰，如图2-右下。
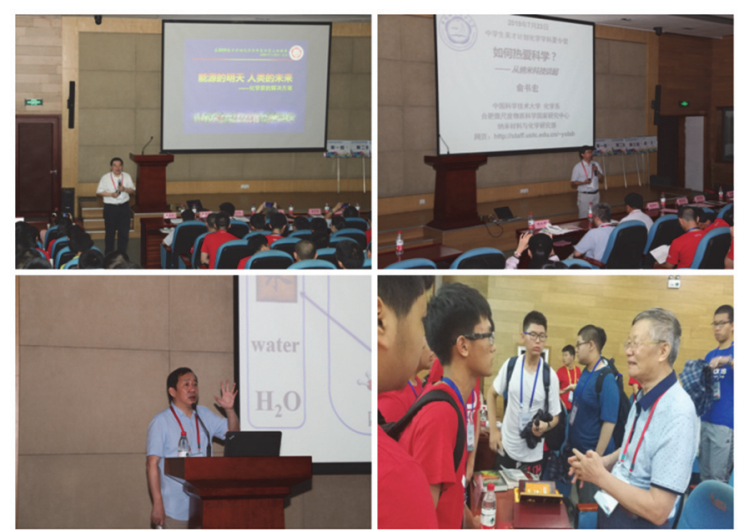

图2 教授讲座与师生互动 


\section{3 探索实验亲实践: 脚踏实地, 理论付诸实践}

化学是一门动手操作性很强的学科, 通过实验室进行化学教学可以更好地激发学生的学习兴趣, 提高学生的动手实践能力, 但是要想取得更好的实验结果, 一定要有充足的理论知识作为基础, 所 以实验课是理论知识的验证, 而理论则是实验的基础, 两者相辅相成、不可分割 ${ }^{[5]}$ 。我国目前部分中 学对实验教学的重视程度不够, 由于高考受多种条件的限制, 对化学实验教学的考查只能以笔试的 形式进行。有些学生甚至从未接触过实验仪器, 对实验的认知只是停留在书本的 “死记硬背” 知识 点上, 这种现象禁锢了学生对化学的兴趣和好奇心, 而且不利于学生观察能力和动手能力方面的培 养，与拔尖人才培养理念相悖。

古语有云: “纸上得来终觉浅, 绝知此事要躬行”, 化学实验教学对于帮助学生形成化学概论, 巩 固化学知识, 获得化学实验技能, 培养实事求是、严肃认真的科学态度具有重要的意义, 在培养学 生观察能力和实验能力方面均有不可或缺的作用 ${ }^{[6]}$, 更能培养学生的思维、创新、实践的能力。夏令 营活动开展课题实验, 带中学生们走进大学化学实验室, 引导激发学生们对化学学科的兴趣和热情, 通过实验直观而又深入地了解化学, 并在实验中体验化学的奥秘, 下面以 “饮料中 “珍珠” 的制备 和创意研究” 为例详述之。

\section{1 安全意识培养}

在化学实验过程中, 中学生往往会忽视各种实验要求和注意事项, 安全意识很薄弱, 因此, 在 夏令营探索实验活动中, 以大学的化学实验安全规范和要求, 采取 “安全准入+安全教育+教师巡视 提醒” 多种形式, 加强对学生的安全知识教育, 强化学生的安全意识, 相信这些将在学生们心中生 根发芽, 有效避免实验安全事故的发生, 见图3。
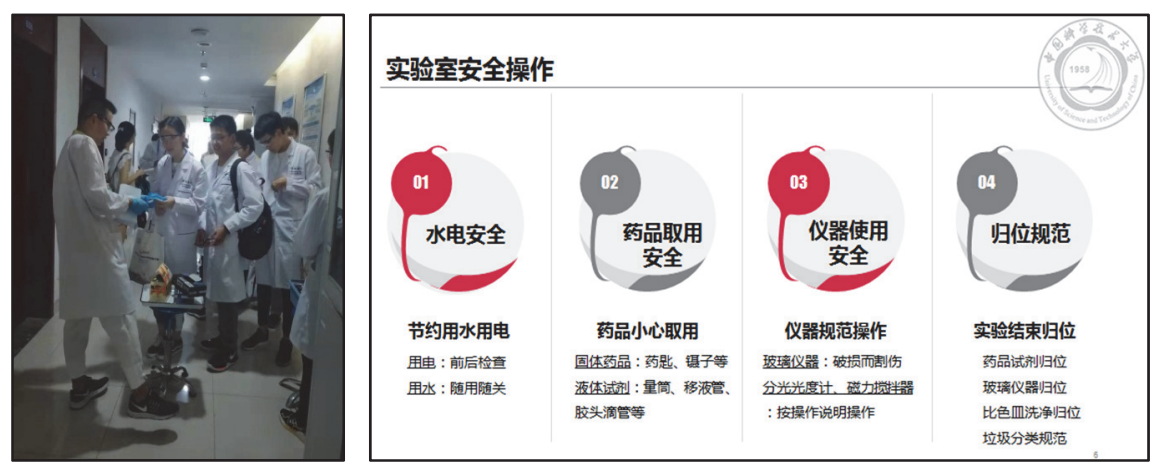

图3 实验室安全准入(左)、安全知识教育PPT(右)

\section{2 探索实验过程}

\subsection{1 实验设计}

在实验设计上, 我们选取了大学化学中经典分析化学实验 “饮料中 “珍珠”的制备和创意研究”, 操作难度适中, 贴近生活, 趣味性强, 学生可用实验制备的五颜六色的产物海藻酸盐凝胶自行进行 创意造型设计。

\subsection{2 实验原理}

海藻酸钠是褐藻细胞壁的主要成分之一, 它是由 $\beta$ - $\mathrm{D}$-甘露糖醛酸 $(\mathrm{M})$ 残基和 $\alpha-\mathrm{L}-$ 古洛糖醛酸 $(\mathrm{G})$ 残基通过 $1 \rightarrow 4$ 糖苷键连接而成的线性高分子。 $\mathrm{Ca}^{2+} 、 \mathrm{Cu}^{2+} 、 \mathrm{~Pb}^{2+}$ 等金属离子与 $\mathrm{G}$ 残基的 $-\mathrm{OH}$ 和 $-\mathrm{COOH}$ 相互作用, 使得海藻酸盐分子间发生交联, 进而形成海藻酸盐凝胶。本实验利用锐孔法 将海藻酸钠溶液挤出形成球形液滴, 滴入 $\mathrm{CaCl}_{2}$ 溶液中交联获得海藻酸钙凝胶小球(微胶囊), 或者连 续挤出, 形成凝胶条。

\subsection{3 实验考核}

实验的考核是采取过程式考核方法, 即: 从实验操作、实验记录、实验结果、团队合作及创新 
性五个方面对学生进行全方位考核, 在公平公正的环境下促使学生专注于实验本身, 有利于充分调 动学生学习的积极性和主动性, 培养学生的动手能力和创新意识, 为学生今后的学习和工作都打下 坚实的基础。评分表见图4。

\begin{tabular}{|c|c|c|c|c|c|c|c|c|c|c|c|}
\hline \multicolumn{12}{|c|}{$\begin{array}{l}\text { 2019年英才计划化学学科夏令营探索实验项目 } 1 \\
\text { 饮料中 “珍珠” 的制备和创意研究 } \\
\text { 评分表 } \\
\text { 化学实验教学中心 } 601 / 602 / 603\end{array}$} \\
\hline \multirow{2}{*}{ 序学 } & \multirow{2}{*}{ 姓名 } & \multicolumn{4}{|c|}{ 实验操作(40分) } & \multirow{2}{*}{ 实验记录(10分) } & \multicolumn{2}{|c|}{ 实验结果(30分) } & \multirow{2}{*}{ 团队合作(10分) } & \multirow{2}{*}{ 创新性(10分) } & \multirow{2}{*}{ 备注 } \\
\hline & & 微胶囊制备(15分) & 过滤(10分) & \begin{tabular}{|l} 
移液(8分) \\
\end{tabular} & 比色血(7分) & & 均一性(20分) & 吸附(10分) & & & \\
\hline \begin{tabular}{|l|}
1 \\
\end{tabular} & & & & & & & & & & & \\
\hline \begin{tabular}{|l|}
2 \\
\end{tabular} & & & & & & & & & & & \\
\hline \begin{tabular}{|l|}
3 \\
\end{tabular} & & & & & & & & & & & \\
\hline \begin{tabular}{|l|}
4 \\
\end{tabular} & & & & & & & & & & & \\
\hline
\end{tabular}

图4 英才计划化学学科夏令营探索实验项目评分表

\subsection{4 成果展示}

自制创意作品, 这个环节让学生们从呆板枯燥的书本知识跳脱出来, 充分发挥自己的想象力和 创造力。学生们经过几个小时坚持不解的努力, 每份作品都充满着活力, 见图 5。一位学生评价: 原 来认为大学中的化学实验课是晦涩难懂的, 但是经实际体验后, 更显平易近人, 化学也可以这么有 趣, 创意无限, 收货满满。
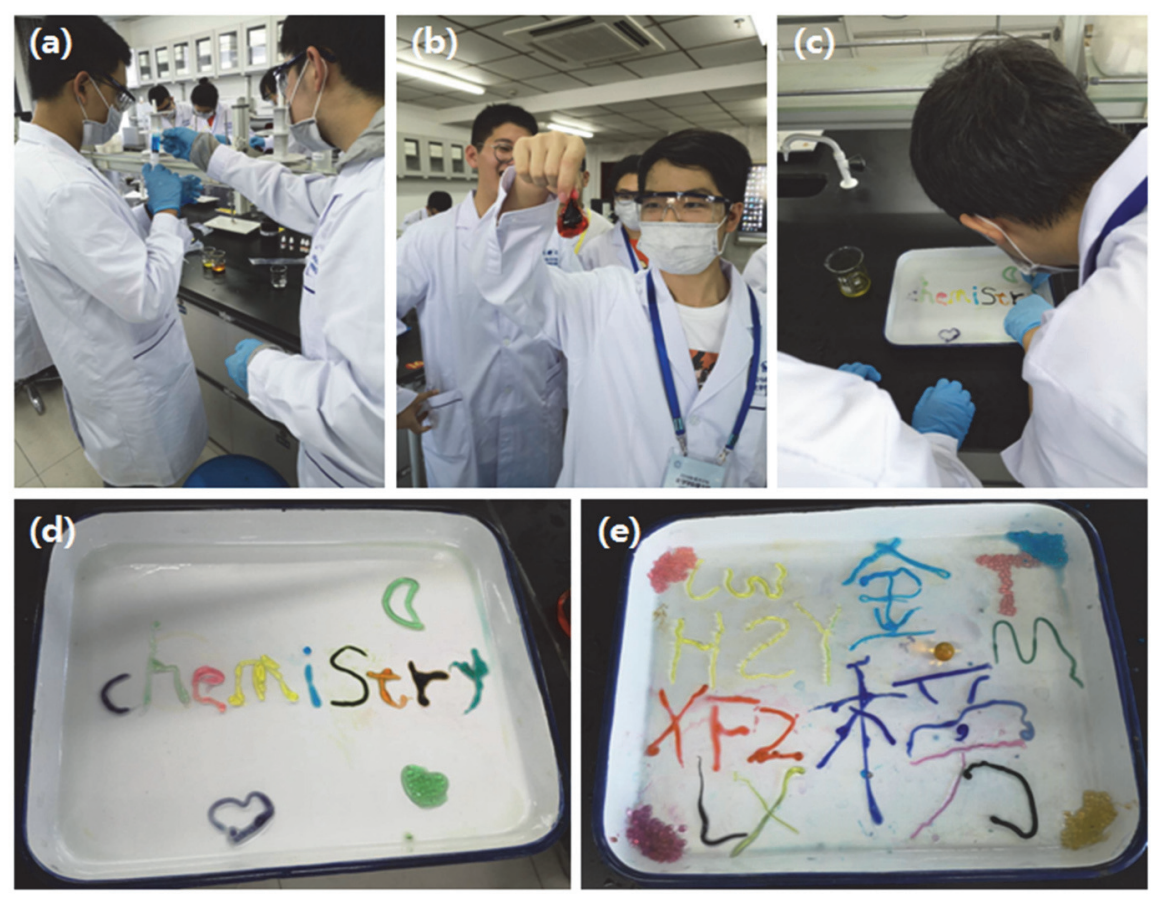

图5 学生实验课题探索过程 $(a, b, c)$; 学生创意作品展示 $(d, e)$

\subsection{5 汇报交流}

为培养学生良好的实验习惯, 探索实验实践中要求学生书写实验报告。活动后期, 还安排学生 们就实验课题成果进行汇报与交流, 分享在实验中的收获与感想, 分析在实验过程中所出现的问题, 对未来的大学化学学习做出展望。

\section{4 参观国家大科技装置：总结分享，展望未来之途}

活动期间, 参观中国科学院等离子体物理研究所的超导托卡马克实验装置, 中国科学院强磁场 
科学中心的稳态强磁场实验装置和中国科学技术大学国家同步辐射实验室这三个国家重大科技基础 设施, 更是让学生们体会到我国科技的飞跃发展。参观中国科学技术大学校史馆让中学生们了解到 “红专并进, 理实交融” 的理念; 与中国科学技术大学优秀大学生面对面的交流, 营员们学到了宝贵 的学习经验, 了解有趣而丰富的大学生活, 以及对忙碌而充实的科研生活充满好奇。夏令营的生活 虽短暂, 却能让营员们更好地认识化学, 从而相约未来。

\section{5 结语}

本次夏令营活动发挥中国科学技术大学化学学科优势, 开展科研讲座, 专家们以专业的理论、幽 默风趣的语言、丰富生动的互动带领师生进入了化学科学的殿堂; 组织实验探索, 培养中学生的创 新实践精神, 也突出体现化学学科的趣味性与实用性; 参观国家重大科技基础设施等活动, 让学生 体会到我国前沿科技的飞速发展, 更是激发了学生的爱国热情和民族自豪感。科研梦想的种子已然 播种, 等待生根发芽。化学教学不是简单地让学生去做, 而是如何走入学生内心, 让其直观感受化 学的魅力并产生兴趣, 所谓 “兴趣是最好的老师”, 兴趣指引下的中学生会将 “我被教” 自行转化成 “我要学”, 这就是英才计划夏令营活动设计实验项目的初衷。

英才计划的计划和实践, 将中学与大学有机衔接, 对推进拔尖型科技人才的培养, 有着举足轻 重的作用。因此, 在未来的工作中继续探索如何培育创新人才脱颖而出的良好氛围, 为优秀人才的 成长提供顺畅通道, 为科技创新人才培育和发展提供良好环境和条件。

\section{参 考 文 献}

[1] 伍春香, 王丽娜, 杜瑞颖, 吴黎兵, 刘树波, 王寒. 计算机教育, 2018, No. 7, 135.

[2] 杜朋林, 吴静怡. 创新人才教育, 2017, No. 3, 52 .

[3] 朱莉莉. 知识经济, 2018, No. 4, 177.

[4] 王华. 中国科技教育, 2015, No. 11, 18.

[5] 星生州. 教育, 2015, No. 8, 172.

[6] 张利玲. 明日, 2018, No. 6, 205. 